\title{
A perda do contato vital com a realidade na esquizofrenia, segundo Eugène Minkowski
}

\author{
Mário Eduardo Costa Pereira
}

Em sua edição de dezembro de 2000, a Revista Latinoamericana de Psicopatologia Fundamental apresentava a tradução de um fragmento extremamente significativo das considerações finais do Traité de Psychopathologie (1966), de Eugène Minkowski (1885-1972), intitulado "Breves reflexões a respeito do sofrimento (aspecto pático da existência)". Quase quatro anos mais tarde, o presente número da Latino retorna à obra desse grande psiquiatra franco-polonês, agora para focalizar uma de suas contribuições mais precoces e decisivas para o campo da psicopatologia: a noção da perda do contato vital com a realidade como perturbação essencial da esquizofrenia. Tal proposição constituiu o tema de sua tese de doutorado em medicina, defendida em 1926, em Paris, sob a direção de Henri Claude, e permaneceu como um dos pilares de sua teoria da psicopatologia ao longo de toda sua obra.

Retomaremos, a seguir, alguns elementos histórico-biográficos de Minkowski - muitos dos quais já expostos na apresentação que fizemos à tradução precedente (Pereira, 2000, p. 153-5) - colocando-os em relação com a produção de sua teoria, com o objetivo de melhor situar o contexto da produção do escrito ora traduzido, bem como de explicitar sua importância específica nos debates psicopatológicos sobre a esquizofrenia.

Eugène Minkowski nasceu em 17 de abril 1885 na cidade russa de São Petersburgo. Originário de uma família judaica instalada na Polônia, Minkowski realiza seus estudos de medicina em Varsóvia, prosseguindoos em Munique. 
Durante os anos da Primeira Guerra Mundial, busca refúgio em Zurique, vindo a ser aceito como assistente de Eugen Bleuler, no Hospital Burghölzli.

Naquela renomada instituição acadêmica e psiquiátrica, Minkowski tomou contato com a recém-criada categoria de "Esquizofrenia” e com abordagem psicopatológica bleuleriana.

Desde cedo, sua própria perspectiva psicopatológica foi profundamente marcada pela fenomenologia de Husserl, pela leitura das obras filosóficas de Heidegger e de Bergson e pela interlocução com Ludwig Binswanger.

Em 25 de novembro de 1922, na memorável 63a Jornada Científica da Sociedade Suíça de Psiquiatria, realizada em Zurique, Minkowski apresenta seu famoso trabalho intitulado: "Um caso de melancolia esquizofrênica”, o qual foi seguido pela conferência de Binswanger (1971, p. 79-117): “De la phénoménologie”. Essa data entraria para a história como marco da fundação da psicopatologia fenomenológica.

Apesar da grande erudição filosófica de Minkowski, e de seu profundo conhecimento de autores como Heidegger e Bergson, sua obra psicopatológica diferentemente daquela de Binswanger - jamais se organizou em torno de um debate direto com a filosofia e com a fenomenologia. Ele buscava, antes de tudo, o respeito à complexidade dos dados empíricos colocados em evidência pela experiência psiquiátrica e procurava fundar sua psicopatologia sobre bases clínicas concretas.

Minkowski instala-se em Paris após a guerra e, em 1926, defende sua “Thèse de Doctorat en Médecine” sobre a perda do contato vital com a realidade na esquizofrenia. Vincula-se, em seguida, a Henri Ey e a Paul Schiff, com quem criaria o grupo “Évolution Psychiatrique”, uma das mais significativas experiências teóricas e de interlocução em psicopatologia no século XX. Desse mesmo grupo viriam a participar Lacan e Pichon.

Em função de seu percurso tão singular, Eugène Minkowski foi o principal introdutor do pensamento de Bleuler no contexto francês, em particular de sua noção de "Esquizofrenia”. Mesmo sem aderir totalmente às suas teses, Minkowski foi também o introdutor na França da Daseinanalyse de Binswanger.

Da mesma forma, Minkowski mantém, desde sua tese, diferenças marcantes em relação às revolucionárias proposições bleulerianas.

A psicopatologia de Bleuler, diferentemente da ênfase descritiva e classificatória de Kraepelin, fundava-se na busca da delimitação precisa do “transtorno gerador” do distúrbio mental. Tratava-se, sobretudo, de identificar a perturbação psicopatológica fundamental sobre a qual instala-se o quadro clínico observável. Sob essa perspectiva, os sintomas primários da esquizofrenia exprimiriam uma profunda alteração da personalidade, derivada do conjunto de reações mentais ao transtorno gerador. Este elemento psicopatológico primário 
era, segundo Bleuler, claramente identificável na esquizofrenia: a desagregação, a clivagem da personalidade, a esquize do eu. Nas palavras do próprio Minkowski: "Em vários pontos eu me afasto de Bleuler, e mais particularmente, sob a influência de Bergson, eu vejo o transtorno inicial da esquizofrenia, não em um afrouxamento das associações, mas na perda de contato vital com a realidade; é dessa perda de contato que eu tento deduzir os sintomas cardinais e as manifestações mais características da esquizofrenia”.

Nesse contexto, os sintomas mais exuberantes desse grave distúrbio mental - tais como os delírios, alucinações auditivas e visuais, comportamento bizarro e despersonalização - constituem, na verdade, tão-somente um conjunto solidário de perturbações e de tentativas de compensação da profunda desorganização psíquica produzida pelo transtorno gerador. Assim, as idéias delirantes, por exemplo - tão marcantes na apresentação clínica da esquizofrenia - constituem apenas fenômenos secundários, esforços para inscrever subjetivamente a situação alterada na qual se encontra a personalidade que se desagrega. O delírio exprime, por assim dizer, a tentativa de introdução de uma nova ordem racional e de sentido em um mundo novo, incompreensível e fragmentado, mergulhado em uma atmosfera de medo e de angústia.

A crítica de Minkowski partirá de uma recusa radical da abordagem psicopatológica que se apóia em uma pretensa psicologia das faculdades mentais. Para o autor do Traité de Psychopathologie, a fragmentação da experiência psíquica em compartimentos relativamente estanques como "memória”, "pensamento", "afetividade” e "senso-percepção", ainda que concebidos em estreita inter-relação, na verdade introduz uma artificialidade incompatível com a complexidade do processo psíquico observado em sua totalidade.

É nesse sentido que sua abordagem fenomenológica vem introduzir uma nova metodologia em psicopatologia, visando a descrição da experiência psíquica enquanto tal. Contrário a todo reducionismo objetivista dos fenômenos psíquicos, o método fenômeno-estrutural de Minkowski baseava-se no encontro mais próximo possível com o humano. Não se limitava a descrever a experiência vivida [Erlebnis] do indivíduo em sofrimento mental, mas ligava-a, também, a "uma estrutura que organiza as perturbações, a uma forma, a um fundo mental concebido de modo dinâmico numa perspectiva que pode ser, no plano fenomenológico, qualificada de genético-estrutural”.

Dessa maneira, a referência fenomenológica de sua psicopatologia o conduz a dar prioridade à descrição da totalidade do fenômeno examinado, à sua estrutura. Não obstante, tal busca da apreensão da estrutura não se confunde com a abordagem estruturalista que viria a dominar as ciências humanas na França a partir dos anos 1940, com Lévi-Strauss, Jackobson e Lacan. Este último, juntamente com Henri Ey, reconheceu em Minkowski o introdutor da noção de 
“estrutura” na psicopatologia francesa. Para este, a "estrutura” referia-se a uma consistência fenomenológica, enquanto, para aqueles, dizia respeito à organização constante de uma certa lógica simbólica.

O método de Minkowski consistia, antes de tudo, tal como sugere LantériLaura (1997, p. 9-17), em uma busca do concreto. Não se deve perder de vista que Minkowski era um leitor rigoroso do "Ensaio sobre os dados imediatos da consciência”, de Bergson. Tratava-se, pois, de considerar que "as reações do clínico em presença de um paciente acompanhado de modo prolongado e cotidiano podem se tornar um meio de investigação das perturbações mentais, sob a condição de se conduzir uma pesquisa que não se perca nem na Einfühlung, nem no irracional”. Após certo tempo de exposição e de abertura ao fenômeno, este se dá a conhecer enquanto tal, em sua totalidade. Não consiste, portanto, em uma abordagem introspectiva, mas no esforço fenomenológico de se expor à própria coisa em apreço, de deixá-la se expressar como experiência imediata à consciência.

É nessa perspectiva, também, que Minkowski assume resolutamente a concepção de que a psicopatologia constitui uma psicologia do patológico e não uma patologia do psicológico. Essa última proposição obriga o clínico e o pesquisador a recorrerem a uma incerta referência à noção de "normalidade", concebida como padrão absoluto a partir do qual se definem os desvios mórbidos da vida mental.

Ao contrário, ao conhecer a experiência humana como intrinsecamente pática, ou seja, fundada sobre o pathos da paixão e do sofrimento, a psicopatologia tem por tarefa a descrição de formas singulares de existência e de estar-no-mundo. Com tal atitude teórica e metodológica, Minkowski aborda o fenômeno esquizofrênico visando exprimir o fundo existencial sobre o qual este transcorre, antes de realizar um recenseamento de sintomas e de alterações das faculdades da alma.

É assim que Minkowski, diferentemente de seu mestre Bleuler, propõe que o transtorno essencial da esquizofrenia consiste na perda do contato vital com a realidade. É a partir dessa condição mórbida irredutível que o estado psicopatológico se instala e em torno do qual se implantam os sintomas secundários.

A harmonia com a vida é o outro nome de seu conceito de contato vital com a realidade. Diz o autor:

Devemos sublinhar aqui o termo "vital", pois o que o esquizofrênico perde não é a possibilidade de um simples contato sensorial com o ambiente, mas a dinâmica desses contatos, para tudo dizer, o que faz o caráter vivo da relação do sujeito ao outro.

Quando um dos fatores essenciais da vida psíquica vem a faltar, aqueles que permanecem intactos tendem à se reagrupar para estabelecer, na medida do 
possível, uma forma de novo equilíbrio. Este, ainda que apresentando características profundamente mórbidas, constituem, mesmo assim, como uma prancha de salvação para a personalidade em fracasso (...). Ele tenta, dessa forma, salvaguardar seu aspecto humano.

É dessa postura subjetiva diante do fracasso psíquico que se originam aquilo que Minkowski denominou “as atitudes mórbidas”, das quais se destacam o racionalismo e o geometrismo mórbidos, as atitudes antitéticas e a atitude interrogativa: o esquizofrênico, incapaz de assimilar o que é da ordem do movimento e do tempo que passa, "tende a construir seu comportamento de fatores e critérios cujo domínio próprio, na vida normal, é unicamente a lógica e as matemáticas”.

Fundantes da psicopatologia esquizofrênica, as condições ditas "autísticas" são descritas por Minkowski sob duas formas principais:

1) Autismo rico: tem o sonho como protótipo. Caracteriza-se pela construção de um mundo imaginário. Os complexos pessoais desempenham um papel preponderante.

2) Autismo pobre: mostra a perturbação esquizofrênica em estado puro, parada ou fratura do elã pessoal.

Assim, pela noção de perda de contato vital com a realidade, Minkowski entende demonstrar que a perturbação esquizofrênica baseia-se na ruptura radical com o mundo humano, com o laço social. O sujeito exclui-se à abertura dialética com o outro humano, mergulhando em uma vivência de absurdo e de sem-sentido que impõe uma reconstrução forçada e artificial do sentido de sua existência, de seu corpo e de seu estar-no-mundo.

\section{Referências}

Binswanger, L. De la phénoménologie. In: Introduction à l'analyse existentielle.

Paris: Minuit, 1971.

LantÉri-Laura, G. Introduction à la pensée rigoureuse d'E. Minkowski. In: Minkowski, E. Au-délà du rationalisme morbide. Paris: L'Harmattan, 1997.

Minkowski, E. Breves reflexões a respeito do sofrimento (aspecto pático da existência).

Revista Latinoamericana de Psicopatologia Fundamental, São Paulo, ano III, n. 4, p. 156-64, dez/2000.

Pereira, M.E.C. Minkowski ou psicopatologia como psicologia do pathos humano. Revista Latinoamericana de Psicopatologia Fundamental, São Paulo, ano III, n. 4, p. 153-5, dez/2000. 